\title{
Lung cancer screening: targeting the hard to reach-a review
}

\author{
Guido Van Hal, Paloma Diab Garcia \\ Department of Social Epidemiology and Health Policy, University of Antwerp, Belgium, Antwerpen, Belgium \\ Contributions: (I) Conception and design: All authors; (II) Administrative support: University of Antwerp Inter Library Service; (III) Provision of study \\ materials or patients: None; (IV) Collection and assembly of data: All authors; (V) Data analysis and interpretation: All authors; (VI) Manuscript \\ writing: All authors; (VII) Final approval of manuscript: All authors. \\ Correspondence to: Guido Van Hal. Social Epidemiology and Health Policy, University of Antwerp, Universiteitsplein 1, 2610 Antwerpen, Belgium. \\ Email: guido.vanhal@uantwerpen.be.
}

\begin{abstract}
Lung cancer (LC) is the leading cause of cancer death in the USA for both men and women, and also worldwide, it is the commonest cause of cancer death. The five-year survival rate for LC depends on the stage at which it is diagnosed. It is over $50 \%$ for cases detected in a localized stage but when the disease has spread to other organs, the five-year survival rate is only $5 \%$. Unfortunately, only $16 \%$ of LC cases are diagnosed at an early stage. In 2013, the US Preventive Services Task Force (USPSTF) recommended annual LC screening with low dose chest computed tomography (CT) in adults aged 55 to 80 years who have a 30 pack-year smoking history and currently smoke or have quit within the past 15 years, based on the evidence from the National Lung Screening Trial (NLST) in the USA. When it comes to recruiting the target group for lung cancer screening (LCS), there are several barriers to overcome, such as whom exactly to include, where to find the target group, how to convince the target to participate or how to attract participants from all socioeconomic groups. The aim of this review is to find out what is already known about how the target group for LCS can be contacted and how participation can be improved, since uptake is a key issue in every (cancer) screening program. A review of the literature was conducted using 'lung cancer screening and participation and uptake' as search string. We searched in Web of Science and PubMed for reviews, systematic reviews and articles, published between 2015 and 2020. Compared to the target groups for screening in the long-running cancer screening programs of breast, cervical and colorectal cancer, there are several additional obstacles regarding defining, locating and recruiting of the target group for LCS. Shared decision-making is crucial when we want to reach the hard to reach for LCS and it should be improved, by educating primary care practitioners about LCS guidelines and providing them with the necessary tools, such as decision aids, to facilitate their job in this respect. Moreover, the information materials should be more tailored to specific groups who participate least.
\end{abstract}

Keywords: Lung cancer screening; hard-to-reach; participation; uptake; attendance

Submitted Mar 31, 2020. Accepted for publication Jun 19, 2020.

doi: $10.21037 /$ tlcr-20-525

View this article at: http://dx.doi.org/10.21037/tlcr-20-525

\section{Introduction}

Lung cancer (LC) is the leading cause of cancer death in the USA for both men and women (1). Also worldwide, LC is the commonest cause of cancer death (2).

Of all LC cases, smoking is implicated in more than $90 \%$ and prognosis is poor, with mortality close to $85 \%$ (3). However, the earlier the stage at which LC is detected, the better the prognosis. In November 2011, the first large multicenter randomized control trial-the National Lung Screening Trial (NLST) in the USA—released their results that showed that screening with chest low-dose computed tomography (LDCT) could reduce LC mortality by $20 \%(4,5)$. In the meantime, the NELSON trial in The Netherlands and Belgium also released its results (6). They found that screening with chest LDCT can reduce cause- 
specific mortality in males by $26 \%$. Based on the results of the NLST, the US Preventive Services Task Force (USPSTF) recommended annual lung cancer screening in 2013 (Grade $\mathrm{B}$ recommendation). However, as with any cancer screening program, it is important that lung cancer screening (LCS) is implemented appropriately. A data infrastructure that comprehensively captures information about the screening continuum, including eligibility assessment as a starting point, is a prerequisite, so that the benefits are not outweighed by the harms (7). A problem (cancer) screening programs can face, is that the target group does not attend, which endangers the existence of the program. Although it is clear that people can always refuse to participate after being well-informed about the benefits and harms of a (cancer) screening program, oftentimes other issues are playing a role. In these cases, more than unwillingness to participate, a lack of knowledge, not being familiar with the program or practical issues can be the reasons of non-attendance. In these cases, removing the barriers regarding these issues can help increase the participation rate. Therefore, this review will present an overview of these reasons of non-attendance and what can be done about it.

Nonetheless, contrary to breast, cervical and colorectal cancer screenings, there is much less experience in organizing LCS. Especially when it comes to recruiting the target group, there are big differences between the cancer screening programs already running for decades and LCS. This mainly has to do with two issues: (I) the target group for LCS is not mainly defined by age and sex, but is based on the risk of getting LC and (II) the fact that the risk of getting LC is highly correlated with smoking, an unhealthy life style, which could also negatively affect participation in LCS. This can result into very low participation rates. An abstract presented at the Annual Meeting of the American Society of Clinical Oncology (ASCO) calculated that despite the recommendation of the USPSTF in the USA only about $2 \%$ of the eligible populations are being screened for LC (8). However, in the states of Florida, Nevada, and Georgia, the collective rate in 2017 was much higher at $16.3 \%(9)$.

The aim of this review is therefore to find out what is already known about reaching the hard-to-reach for LCS, and how participation can be improved, since uptake is a key issue in every (cancer) screening program.

\section{Material \& methods}

The review focused on studies which centered on 'lung cancer screening and participation' and 'uptake', which also was the search string. Articles included had to have been published between 2015-2020. Furthermore, they had to be in English, Spanish, French or German and be a review, systematic review or an article. The search tools used were Web of Science and the advanced search function in PubMed. Additionally, the references of a key review by Field et al., 2016 in Lung Cancer and those of a presentation on the European Radiology Society (ERS) Research Seminar-Lung Cancer Screening: from Trial to Practice, Barcelona, 11th of December 2018, entitled "Participation in lung cancer screening: lessons learnt from the past" by Van Hal, were screened $(10,11)$. Once all articles were identified by our inclusion criteria they were further screened by title, then by abstract and finally by full text to make sure that they were appropriate to answer our research question. An overview of the selection procedure of the articles can be found in Figure 1. A list of all selected articles can be found in Table S1.

\section{Results}

From the selected articles, several topics emerged as important, and were mentioned several times. We also used them as headers for this results section. The most important findings are summarized in Table 1.

\section{How is the target group for LCS defined?}

The USPSTF defined the target group for LCS as current or former smokers aged 55 to 80 years who have a smoking history of 30 pack-years or more and have smoked within the past 15 years (4). This is an often used definition of the target group, but in the NELSON study, a large LCS trial in The Netherlands and Belgium, the target group was defined as current smokers and former smokers between 50 and 75 years with 10 years or less of cessation, who smoked more than 15 cigarettes daily for over 25 years or more than 10 cigarettes daily for over 30 years (12). Moreover, besides only defining a target group based on general guidelines regarding smoking history and age, it is also possible to define it based on the individual risk to get LC. Individual risk-based criteria have a higher efficiency since it allows for high-risk smokers who would not be eligible for screening based on the USPSTF criteria to be screened. They recommend that eligibility for LCS be based on a LC risk tool which is founded on surpassing a cost-effective risk-threshold which balances computed tomography (CT) 

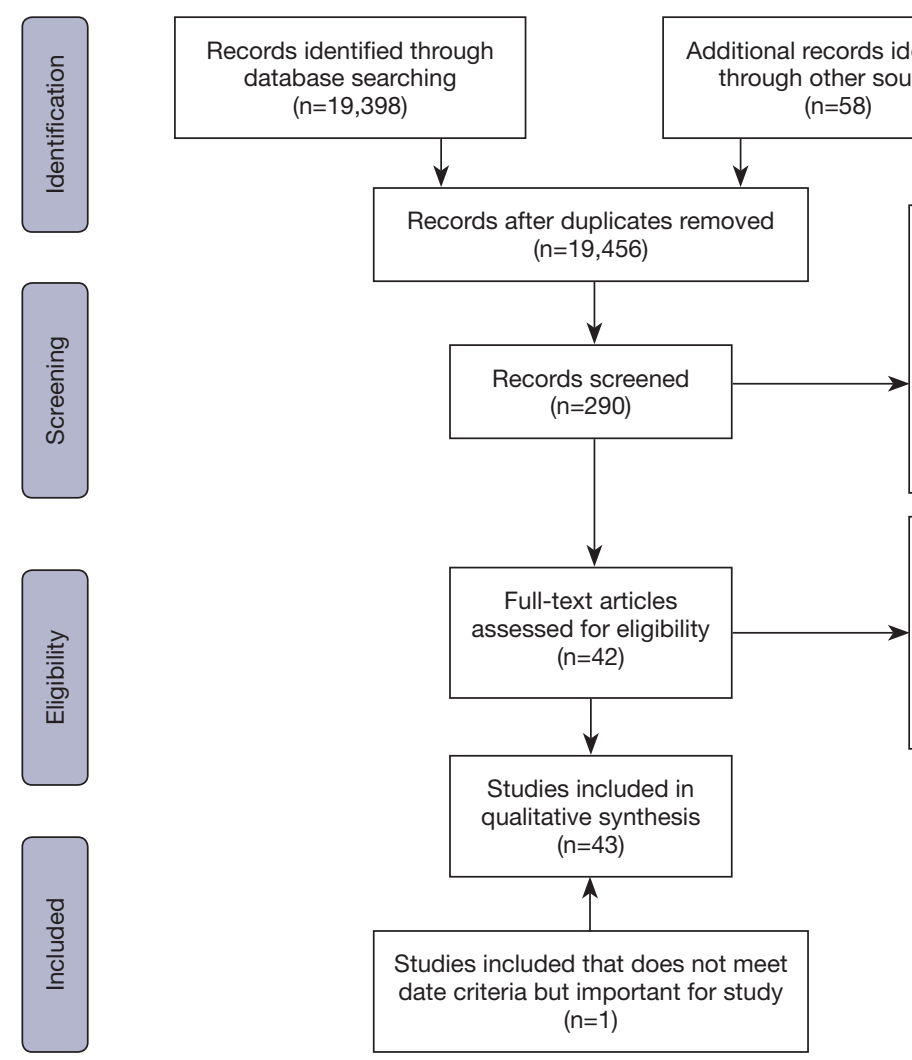

Records excluded based on eligibility criteria $(n=19,166)$

Eligibility criteria includes: 2015-2020 ( $n=14,107)$

Language (English, French, German, Spanish) $(n=167)$

Humans (species) $(n=1,356)$

Article type (article, review, systematic review) $(n=3,054)$

Subject (cancer) $(\mathrm{n}=20)$

Age (Aged, +45$)(n=462)$

Full-text articles excluded, with reasons $(n=248)$

Based on the title did not respond to our research question $(n=207)$

Based on abstract/text: Not focused on lung cancer, does not focus on participation to screening, focuses on promoting smoking cessation... ( $(n=41)$

Figure 1 PRISMA flow diagram of selected articles in Web of Science and PubMed on 'lung cancer screening' AND 'participation' AND 'uptake' [2015-2020].

Table 1 What are the barriers and possible solutions to reach the hard-to-reach for lung cancer screening?

How is the target group for lung cancer screening defined?

Barrier: no straight-forward definition whom to screen

Possible solutions: using the definitions of the NLST and NELSON study; using individual risk-based criteria using lung cancer risk tools Locating the target group: an extra step to take

Barrier: no list of the target group readily available

Possible solutions: (electronic) primary care records; intake questionnaires (e.g., during mammography screenings or smoking cessation counseling); using patient navigators

Recruitment: extra barriers specific for (ex-)smokers?

Barrier: smokers tend to be reluctant to participate in LCS

Possible solutions: adapted educational material to the different literacy levels and backgrounds

Barrier: gaps in knowledge about screening guidelines and reimbursement in family physicians

Possible solutions: providing primary care practitioners with the necessary tools, such as decision aids

Recruitment: general barriers

Barriers: barriers related to the screening test and the screening program

Table 1 (continued) 
Table 1 (continued)

Possible solutions: by shared decision-making, potential participants can be informed about the harms and benefits of screening, so that an informed choice can be made

Barriers: financial costs

Possible solutions: providing free screenings or health insurance coverage

Barriers: language and knowledge barriers

Possible solutions: tailored information materials; alternative materials such as an information film and a written booklet

Motivations to be screened-perceived benefits

Possibilities: trust in referring physicians

Possibilities: early detection benefits-early diagnosis, a higher chance of survival and potential reassurance

Which subgroups participate less?

Barriers: subgroups participating less: low socioeconomic status

Possible solutions: shared decision-making to better inform this subgroup of potential participants; the use of targeted, stepped and low burden materials; stratifying invitation materials by area-level deprivation

Barriers: subgroups participating less: current smokers

Possible solutions: using patient navigators; a non-confrontational communication strategy

Barriers: subgroups participating less: women

Possible solutions: when women go to radiography practitioners to screen for other types of cancers, this would be an ideal setting to engage them into LCS and educate them as well as help them to stop smoking

License to smoke or teachable moment?

Barriers: lung cancer screening as a license to smoke

Possible solutions: incorporate smoking cessation in the patient-provider discussion about LCS; connect to the patients' personal experience of family/friends with cancer, which will make the importance of screening and smoking cessation more salient and make them more considerate

What can (or should) health care providers and program managers do to reach the hard-to-reach?

Possibilities: shared decision-making, patient-provider discussions

Possibilities: alternative information material

Possibilities: personalized screening material

Possibilities: patient navigation

Possibilities: reminders for re-invitation; having screening programs in the weekends or evenings; providing shuttling or uber vouchers; sending reminders by email or SMS in a patient preferred language; deploying mobile CT scanners; offering screening services in a freestanding program where multidisciplinary teams and appropriate infrastructure can be brought to bear; offering lung cancer screening for free

LCS, lung cancer screening; NLST, National Lung Screening Trial.

screening benefits and harms (13). There can, indeed, be very big differences within the target group as defined by the USPSTF or the NELSON study. When using the $\mathrm{PLCO}_{\mathrm{m} 2012}$, a LC risk prediction model that has been validated by research teams in several countries, including the United States, Germany, Australia, and Canada, this becomes very clear: 65 years old, current smokers with low education and 30 pack years have a $2.73 \%$ risk of getting LC within 6 years compared to if they had a higher education and were former smokers, their risk would be of $1.42 \%$ (14).

In the UK Lung Cancer Screening Trial (UKLS), the LLPv2 (Liverpool Lung Project) risk model to select 
subjects with $\geq 5 \%$ risk of developing LC in the following 5 years, was used. Based on the results of their study, Field et al. [2016] even recommend starting LCS only at the age of 60 (15).

\section{Locating the target group: an extra step to take}

Once the target group for LCS is defined, the next step is to locate the specific target group. Since there are no lists of these people readily available, the question arises how then, the target group can be located. This depends on the specific conditions of each country. In some countries, a large sample of eligible participants can be reached through primary care records (16). Sometimes, this is even automated, so that primary care providers (PCPs) can identify eligible patients for screening through clinical reminders built into the electronic medical record (EMR), and thus refer them to the program (17). Moreover, the use of an EMR based clinical reminder system has been shown to be accepted by medics and useful to remind them about who is eligible for LCS (18). In a retrospective analysis of EMR data from patients aged 55-80 years with no history of LC who visited a PCP in a large healthcare system in California, documentation of smoking history to determine eligibility had increased from $59.2 \%$ in 2010 to $77.8 \%$ in 2016 (19). Also brief pre-consultation electronic screening forms for chest LDCT eligibility seem to be promising. PCPs reported that patients receiving these e-forms ask questions about LCS during the consultation and it encouraged PCPs to discuss smoking cessation with patients (20).

When this information is not available yet, it must be collected, for instance with intake questionnaires which could be done routinely during (mammography) screenings to identify women eligible for LCS or smoking cessation counselling (21). Radiology groups can create content information for patients to raise their awareness, increase health literacy and invite those eligible to screening (18). Although training and workflow changes will be needed, American College of Radiology mammography screening program directors seem to recognize the benefits of integrating mammography and chest LDCT screening and are receptive to educating and referring women for chest LDCT screening (22). The use of patient navigators could also be considered. A patient navigator helps patients communicate with their healthcare providers. Therefore, they receive the information they need to make informed decisions about their health care. Patient navigators would directly contact current smokers by phone, assess their eligibility, provide information about LCS and help schedule shared decision-making visits and LCS (18).

\section{Recruitment: extra barriers specific for (ex-)smokers?}

After having defined and located the target group for screening, the next step is to recruit the target group. Participation rate is key for the success and even for the (economic) survival of a (cancer) screening program. However, there could be some extra barriers specific to (ex-)smokers in terms of participation in LCS. Smokers tend to have a more fatalistic attitude and are less likely to believe that early detection is associated with a good chance of survival (23). Current smokers tend to not participate mainly due to emotional barriers (24). These emotional barriers could be associated to feelings caused by tobacco dependency (regret, guilt and feelings of entrapment) and stigma (LC as self-inflicted), which were predominant in current and some former smokers (25). Furthermore, according to Ali et al. [2015], smokers reported emotional barriers to justify non-participation (anxiety, fear and the need to avoid LC related information) (23).

Stigma plays an important role in the avoidance of lung screening and negative beliefs towards LCS. This possibly originates through the association that exists between LC, smoking and poor outcomes (26). Wang et al. [2019] also concluded that the following factors influence LCS uptake in participants, specifically smokers: fear of cancer diagnosis, perceived stigma and a sense of being judged for having smoked (18). In a population-based survey of English adults, it was found that a national LCS program would be well-received but that to improve smokers's participation, care should be taken to minimize anxiety and stigma related to LC risk (27). Also a qualitative study in the United States concluded that high-risk participants expressed greater receptivity for promotional materials that did not further stigmatize LC and/or smoking (28). Even quite some time before LCS trials were implemented, Chapple et al. [2004] already established that stigma in smokers can have detrimental effects on their health care (29). In a qualitative study he found that some patients even concealed their illness (LC) because of stigma, shame and blame, while the real culprits were tobacco companies with unscrupulous policies. Stigma also can lead to doctor's delay in LC diagnosis, since they could think it is just 'normal' the patient is coughing because he is a smoker. Every illness, or almost every illness is self-inflicted in some way or another, 
but the stigma is definitely to do with smoking. Chapple et al. [2004] even found that stigma was present in people with mesothelioma or when they had stopped smoking for a long time (29). Also, a study done in Britain (25) found that among smokers $20 \%$ felt that they were being judged by health practitioners and that they smoked too long to have any benefit.

Also, the fact that LC has a poor prognosis, can play a role, as Tonge et al. [2019] discovered (30). The fear of being diagnosed with LC was the main concern behind potential participants not undergoing the screening program, specifically in the low social economical group (25). The fear of being diagnosed with LC was also found by Byrne et al. [2019] and Tonge et al. [2019] to be a barrier to LCS (30,31).

Additionally, smokers believed that their risk for cancer is so high that they will inevitably be diagnosed, thus preferring not to know (30). Quaife et al. [2017] summarized it as follows: the 'better not to know' attitude is one of the main reasons for current smokers not to participate (25). Personalized cancer risk information, however, could maybe result in a decrease of the perceived LC risk in patients referred for screening (32). Also, older patients can perceive themselves as too old to benefit from LCS (33).

Moreover, it is well-known that smokers are proportionally more represented in the lower socioeconomic strata of society and that people with a lower socioeconomic status (SES) generally participate less in preventive health care. Low uptake in low socio-economic groups is mostly associated to fearful and fatalistic beliefs (23). Women and people from low social economic backgrounds tend to have a more widespread pessimistic attitude towards screening (30). Besides, people from lower socioeconomic backgrounds, are often less well informed and have a lower health literacy. This can lead to a lack of awareness about the new screening method for LC, and a lack of knowledge of the eligibility to LCS. In a study with 180 face-to-face interviews among high-risk patients in Malaysia, Kok et al. [2020] found that $76.7 \%$ of the respondents had poor knowledge about cancer screening (34). There are also several misconceptions regarding LDCT, for instance that it should only be needed when there are symptoms or when no chest X-ray has been performed as Draucker et al. [2019] found in their qualitative study with telephone interviews (35).

It therefore is important that LCS educational material is adapted to the different literacy levels and backgrounds (21). A poor knowledge about LCS is also a barrier to shared decision-making, which could be defined as a collaborative process occurring between an individual and their health care provider, where patients are supported to consider their options, which result from the best available scientific evidence and the individual's values and preferences (36).

The benefits and harms of LCS are poorly understood. Many more benefits than harms could be given by current smokers in a qualitative study with telephone interviews. This is due to several factors, such as fear of LC; shame, self-blame and futility — not able to quit so better to detect it early; perceived ability of LCS to quantify and measure risks and harms; deference to providers, lack of interest and understanding of numerical risk information, which are all leading to 'see it more positive than it is' (37).

However, shared decision-making is very important in (cancer) screening: participants should know the harms and benefits of screening and make a decision based on informed choice. Unfortunately, there are also providerinduced barriers. To achieve shared decision-making, it is expected for the health care provider to be knowledgeable regarding LCS. This does not always seem to be the case. A study by Ersek et al. [2016] in 101 family physicians, found that they continued to recommend chest X-ray for LCS instead of LDCT scan (38). They also showed there were gaps in knowledge about screening guidelines and reimbursement in family physicians. Only $21 \%$ of the family physicians presented the risks and benefits of LCS and then recommended screening (38). Also Kanodra et al. [2016] conclude that PCPs were not well informed about the eligibility criteria for LCS; they didn't have enough time, e.g., smoking cessation; relied mainly on the clinical reminder generated by the EMR; were not aware of the brochure outlining the risks and benefits of LCS which was made available to screening sites; said that patients are not interested in harms and benefits when they hear that the test is 'just' a CAT scan; said that patients don't ask questions about their individual risk. This leads to patients just following the recommendations of their PCP (without having had a 'shared decision') (17). Smokers made decisions not based on a mental calculus of the trade-offs, but instead on selective understanding of risks and benefits distorted by feelings aroused by the offer of screening and the recommendations and interpersonal relationships with their primary care physician (37).

Another barrier specific to (ex-)smokers could be comorbidities related to smoking, which is a commonly reported practical barrier to participation (23).

Another barrier linked to the screening test for LC is 
concern about radiation exposure (39). This is confirmed by Lillie et al. [2017] (40). According to their results, one of the main factors that prevent participants from undergoing screening is the fear of cancer-causing radiation.

Tonge et al. [2019] concluded that current smokers had more barriers to screening uptake than ex-smokers (30). Couraud et al. [2018] present data from the UKLS, showing that current smokers participated significantly less than ex-smokers (OR 0.70) (14). Trying to break down those barriers will be a key challenge in LCS programs.

\section{Recruitment: general barriers}

Besides the specific barriers related to smoking and LCS, there are general barriers to participation also occurring in other (cancer) screening programs. These barriers can of course also affect the participation rate for LCS. Several of these general barriers are related to the screening test and the screening program.

Factors which would deter potential participants from participating in LCS are false positive results, knowledge, convenience of LCS and anxiety while waiting for the results (40). The anxiety that is felt when waiting for results and hospital attendance is also mentioned by Tonge et al. [2019] (30).

Other factors that tend to impact participation are difficulties with travelling to attend screening, comorbidities and career responsibilities. In an Australian study, for example, travel time showed up as a driver of choice (33). Furthermore, costs of LDCT can also impact the willingness to participate in screenings (this can be counteracted by providing free screenings or health insurance coverage) (24). Regarding the financial cost barrier, also it was established that the high costs of health care in the US can impact the willingness to be screened especially in immigrant communities (25). The importance of the financial cost as a potential barrier to LCS was also demonstrated by Kok et al. [2020] where they found that $48.2 \%$ of those willing to participate in LCS would be unwilling to participate if they had to pay for the procedure (34).

Current female smokers also seem to have a lower intention to participate (OR 0.28), as was found by Couraud et al. [2018] (14). This was also confirmed with data from the UKLS: female gender meant lower participation (OR $0.64)(14)$.

Another aspect to consider is the language barriers as many communities are not proficient in the language of their home country and would not understand everything especially medical terms (41).

The free choice to participate or not, also seems to be important. Individuals who had to undergo screening as an obligation due to health regulations were significantly less likely to participate in voluntary screening programs (42).

\section{Motivations to be screened—perceived benefits}

Apart from barriers which hinder potential participants to take part in LCS, there are of course also motivational factors to participation.

According to Roth et al. [2018], the four main themes established for screening motivation which should be considered when creating screening plans and programs are: trust in the referring clinicians; early-detection benefits; low or limited harm perception of screening; friends or family with advanced cancer (43). Other authors confirm several of these factors.

\section{Trust in referring clinicians}

Health practitioners have a key role to play regarding providing information and decision making. Their role is so important because the lack of understanding of the information in the patient's perspective could result in no participation. Moreover, many participants relay on their health professional to make the decision for them on whether to undergo screening or not (44).

In a qualitative study by phone, Draucker et al. [2019] observed that physician recommendations were key influencers on deciding whether to be screened or not (35). The quality of the patient/provider communication is most likely to improve screening rates. Smokers prefer to talk about screening options in person with their practitioner instead of receiving a letter as they perceive it as more trustworthy (18). Creating a trustworthy relation with the physician is key since patients will be more willing to undergo screening (43).

Only one study found opposite results. Health care provider recommendations were rated not important in a study by Byrne et al. [2019]. They showed that half the participants had no or little conversation about screening with their PCP; $61.5 \%$ had not sought out any information on screening (31).

\section{Early-detection benefits}

Quaife et al. [2017] found that the common factors observed that influence participation were: benefits of early detection, negative views about the treatment options and the survival 
rate especially in older smokers (25). Also, Tonge et al. [2019] concluded that reasons behind preferring to participate in a screening program were early diagnosis and potential reassurance (30). Communicating the survival benefits of early-stage diagnosis was also found to improve smoker's participation in a study of English adults (27). In a study using the Health Belief Model, Bui et al. [2018] found that the perceived benefits were that screening with chest LDCT helps detect and treat LC (39). An important factor in the decision-making process to be screened for LC is the ability to detect LC early, which was also mentioned in another study (Byrne et al., 2019) (31). Cataldo [2016] also quantified this: Believe that early detection of LC will result in a good prognosis strongly influenced participation (OR 2.7) (45). Furthermore, Kok et al. [2020] came to that conclusion as well: $30 \%$ of respondents believed that early detection of cancer was life-saving; $1 / 3$ believed that early detection of cancer leads to a higher chance of survival; $1 / 5$ believed that early detection of LC would lead to a better chance of surviving (34).

Another factor that positively influences participation was, amongst others the perceived personal risk of LC. Lillie et al. [2017] concluded that it was the most important participation factor (40); Cataldo [2016] found an OR of 1.17 in (ex-)smokers who believed that they are at high risk for LC (45).

According to Prout et al. [2018], reassurance of not having LC is a key motivational factor to participate in LCS (44). This was also seen in the study of Byrne et al. [2019] who found that reassurance that one's lungs were healthy was an important factor in the decision to be screened for LC (31).

\section{Which subgroups participate less or more?}

In light of social equality in preventive health care, it is important that all eligible people can participate in cancer screening and more specifically in LCS. However, this is most of the time not the case. The so-called social gradient in health care, means that people from lower socioeconomic groups, people worse off, people with a migration background, disproportionally participate less in preventive health care. This is also the case for LCS. Several subgroups are identified to be under-represented as participants in LCS.

\section{SES}

High-risk participants which are less willing to undergo CT screening are: older, female, smokers, low socio-economic groups and people with a higher affective risk perception (23). Schütte et al. [2018] came to the same conclusion: among participants in screening programs there tends to be an over-representation of participants with a high social economic status (24). This suggests that the barriers to participate in LCS programs for persons with a low social economic status are too high. Ali et al. [2015] also quantified this phenomenon, they found an OR of 0.56 for eligible people with a lower SES (23). Also, an association between an increase in odds for receiving LCS and having received a college education was observed (21). This finding is worrisome, as it is not ideal that those who are at highest risk (lower SES) are the least likely to take up the offer of screening (15).

\section{Ex-smokers vs. smokers}

Data of the UKLS show that ex-smokers are more likely to respond positively to a screening invitation. Additionally, from the high-risk individuals, ex-smokers were more likely than current smokers to consent to participate in the RCT (49.9\% vs. 42.1\%; $\mathrm{P}<0.0001)(15)$. Barbone et al. [2018] found that participants were more likely to have quit smoking (46). The same results were found by Tonge et al. [2019]: ex-smokers who received an invitation were more prone to participating contrary to current smokers (30). And this was also confirmed in another study in which an over representation of former smokers in screening programs could be observed (26). Ali et al. [2015] found an OR of 0.70 for current smokers (23).

\section{Sex}

High risk women were less likely to participate than highrisk men (23). Schütte et al. [2018] also observed that in most LCS programs there is a higher percentage of male participants compared to women (24). Ali et al. [2015] could quantify this finding: they found an OR of 0.64 for women's uptake (23).

\section{Higher perceived risk}

As smokers already perceive the risk, they may have higher readiness to participate into LCS programs (47). Bui et al. [2018] also established an association between a higher perceived susceptibility and a higher uptake intention (39). Having a history of chronic lung disease, which could be considered as leading to a higher perceived risk for LC, showed a significant association towards willingness to undergo screening with chest LDCT (34). People who 
experienced occupational exposure to dust also showed more willingness to undergo screening with chest LDCT (34). Only Ali et al. [2015] found that a higher affective risk perception led to a lower OR for uptake in LCS (0.52) (23).

\section{License to smoke or teachable moment?}

When organizing LCS, it is indispensable that also smoking cessation is offered to the participants who are still smoking. However, the fact that smokers have the opportunity to be screened, could also be interpreted as a signal for them to keep smoking, 'since the LC will be detected in an early and treatable stage'. On the other hand, the screening could also be considered a teachable moment to get the message across about quitting smoking. What would be the effect of screening on stopping smoking? What is the smoker's attitude towards quitting smoking when participating in LCS?

For most smokers, quitting smoking proves to be difficult. Only half of 61 current smokers who were interviewed face-to-face were keen to be referred to a smoking cessation clinic (34).

Ideally, PCPs could support, coach and advise smokers on how to quit smoking but they usually don't have the time to discuss it. Patients often don't want to quit, unless they are confronted with a severe disease, as was shown by a qualitative study with $13 \mathrm{PCPs}$ and 28 veterans (17).

Nonetheless, only $10.9 \%$ (of 338 respondents who filled out an online survey) believed that a negative CT scan result would mean that they could continue to smoke (45). This would mean that LCS is not considered a license to smoke by the vast majority of potential participants.

Individuals which participate in LCS are even more motivated to stop smoking (10-13\% during the 4-5 years after screening) than the general population. There is also a reduction in relapses. However, there are no consistent long-term effects (48).

On the other hand, implementing smoking cessation in screening could also have an impact on the participation rate, since addiction which is a disorder of low motivation could affect one's confidence in being able to quit smoking which is expected with screening. Thus, this could lead to low participation (25).

\section{What can (or should) health care providers and program managers do to reach the hard-to-reach?}

Once we have evidence on the reasons to participate or not, which groups participate more or less, the barriers to participate and so on, it is important to also take the appropriate measures to actually reach these hard-to-reach. Several suggestions were made by different researchers.

\section{Shared decision-making}

A shared decision-making process between an individual and his or her health care provider is essential to help the individual weigh the benefits and harms specific to their circumstance, resulting in an informed screening decision (49). Many cancer screening managers are fearing a lower participation rate when potential participants are not only informed about the benefits but also about the harms of a screening program. For ethical and fairness reasons, however, it would not be justified to withhold information on potential harms for the participants. In addition, a qualitative study with focus groups showed that a clear and thorough explanation of chest LDCT eligibility, cost, harms, and benefits was of chief importance for both PCP and high-risk participants (28). In the USA, the Centers for Medicare and Medicaid Services approved coverage of screening with chest LDCT for its high-risk members in February 2015 on the condition that patient-provider conversations about LCS participation have taken place (50). It is therefore understandable that some authors want LCS programs to raise awareness, provide education, and promote engagement in shared-decision making, so that individuals have the knowledge and support to determine whether screening is right for them (31).

Roth et al. [2018] summarized the content of these patient-provider discussion as follows: Patient provider discussion about LCS should mainly focus on the: potential impacts of early detection (receive curative intent treatment); potential to avoid chemotherapy; improved survival prognosis; improved health related quality of life (43). Nonetheless, the discussion should find an appropriate balance between benefits and harms, since most participants tend to not understand the harms or do not retain the information about them. Thus, harms should also be taken into consideration (false positives, overdiagnosis and radiation exposure). Evans et al. [2016] for instance, calculated that overdiagnosis in LCS could be as high as $24.8 \%$ (51).

There is a consensus about the fact that there should be a balance between information on benefits and harms. There is less consensus about what exactly should be discussed or what aspects should be stressed.

The significance of radiation exposure from LCS and 
the fact that an unclear result carries a low overall risk of malignancy are very important. A good understanding of these two areas is key since it can have a positive impact on psychological responses to LCS and false positive results thus promoting participation (52).

Some topics can better be dealt with in a careful manner. The 'better not to know' attitude is one of the main reasons for current smokers not to participate. Therefore, it is suggested that emphasizing too much on the risk of having cancer during screening communication is counterproductive and unnecessary as it might polarize decision making. More emphasis should be placed in explaining what early treatment entails with visuals especially the fact that it is not necessary to remove the whole lung for an effective treatment. Thus, a nonconfrontational communication strategy that makes the offer more equal and reduces the blame to improve participation of smokers is recommended (25).

Additionally, smoking cessation should be incorporated in the patient-provider discussion about LCS. It should allow a discussion in which the physician talks about the benefits of smoking cessation without belittling the patient. Thus, counteracting the smoking-related stigma and improving the number of people who undergo screening (40).

It seems that there is a real need for patient-provider discussions about LCS, since a high majority of screening program participants had an insufficient knowledge about the disease, personal threat and screening processes to make an informed choice. It was noted that many participants were misinformed about the optimal time to screen, furthermore their information was from general cancer and not specific to LC (30). Moreover, a study showed that $46 \%$ of participants needed more information about insurance, billing, authorization and reimbursements in order to engage with LCS. This was especially seen in people who are not covered by insurance or have non-private insurance (18).

For a lot of PCPs, it will be a serious burden to have a patient-provider session on LCS with all their high-risk patients. Moreover, many practitioners do not know how to aid patients in a decision-making process. They could be given guides and online classes as well as offering a website in which all resources are available about LCS for patients to review before going to the meeting. Also centralized shared decision-making visits are possible to decrease the burden on practitioners. After screening, patients could meet with practitioners so that they can understand what the follow-up entails and how to interpret possible false positive results (18). According to PCPs themselves, posters in the waiting area, streaming videos, and availability of decision aids in the clinic might help facilitate conversations about LCS. Regarding personalized LC risk prediction calculators, they think this is too difficult to explain to patients or sometimes they don't even really understand it themselves (17).

Another possibility to aid in the informed decisionmaking process is a film. The film would be followed by a session with a health professional to answer any questions and make a decision. The authors suggest that the video (with animations to explain some processes/images) be played in the waiting rooms in a loop so that patients can see it and already have some understanding before the meeting (52).

\section{(Alternative) information material}

Many studies relayed mainly on written information (booklet with invitation) which is not very efficient since they are less accessible to people with low social economic status, low literacy level or older people especially if the invitations are web based (52).

An information film and a written booklet improved objective and subjective knowledge. It significantly reduced decisional conflict contrary to only booklets, however, it did not significantly impact the number of participants who underwent LCS (52).

Digital platforms appear to be an important tool in health promotion and education initiatives related to LCS with the potential to impact care-seeking behavior (statistically significant differences were found between the mean number of scheduled exams during and after the digital awareness campaigns and before and after the digital awareness campaigns) (53).

\section{Personalized screening material}

Since some subgroups clearly tend to participate less in LCS, it might be useful to develop more tailored information material. The use of targeted, stepped and low burden materials was relatively more effective at engaging people with a low social economic background. Stratifying invitation materials by area-level deprivation may be a more equitable way of attracting participants which could reduce inequalities and increase the reduction in LC mortality since more people would be engaged. The fact that it is not 'heavy' information helps to decrease the anxiety/fear that could occur when receiving the information and helps those that have a low literacy capability (16). However, in a recent study, the same authors could not find an effect on uptake of 
a targeted low-burden and stepped invitation strategy versus control (54).

\section{Patient navigation}

A patient navigation program is a proactive approach to helping patients overcome the barriers of cost, fear, and misinformation surrounding a disease and its prevention. The implementation of a patient navigation program resulted in higher rates of participation in LCS contrary to those in usual care. This is mainly because they acted as a liaison between patients and their primary care team. This mitigated the barriers to receiving care and helped high-risk smokers in their decision-making process. This was mainly effective at increasing screening rates in the underserved and low-income current smokers (55). The use of patient navigators increased LCS participation. They would directly contact current smokers by phone and assess their eligibility, provide information about LCS and help schedule shared decision-making visits and LCS (18).

\section{Other suggestions to increase participation also in the hard-to-reach}

Making the importance of screening more relatable to the individual is also key especially in the more resistant. This can be achieved by connecting to the patients' personal experience of family/friends with cancer, which will make the importance of screening and smoking cessation more salient and make them more considerate (43). Tonge et al. [2019] also sees talking with survivors as a possibility to reduce fatalistic fear and to have more information about the effective treatments and screening tests (30). Furthermore, Wang et al. [2019] have a similar suggestion: potential participants can be confronted with testimonies about surviving LC (18).

The use of reminders for re-invitation increased by a further $10 \%$ uptake and allowed some non-responders to overcome non-intentional barriers (16). Ruparel et al. [2019] recommend a repeat information session before each screening appointment (52).

Having screening programs in the weekends or evenings would make it easier for people who are employed/selfemployed to participate (41).

Half the women usually go to radiography practitioners to screen for other types of cancers. Thus, this would be an ideal setting to engage them into LCS and educate them as well as help them to stop smoking (21).

The transport issue can be resolved by providing shuttling or uber vouchers and the language problem by sending reminders by email or SMS in a patient preferred language (18). Potentially mobile CT scanners could be deployed (10).

Screening services may be more effective if offered in a freestanding program where multidisciplinary teams and appropriate infrastructure can be brought to bear (17).

Sometimes, suggestions for measures can be very simple: When LCS is for free, there is no potential financial barrier (39).

\section{Discussion}

The NLST found a 20\% reduction in LC-related mortality with screening with chest LDCT compared to chest X-ray (4). Based on these results, the USPSTF recommended annual lung cancer screening in 2013. Recently, the NELSON study published its results, which also show a substantive reduction in cause-specific mortality for LC when implementing screening with chest LDCT (6).

Nonetheless, one of the main preconditions when implementing cancer screening programs in 'real life', is to reach the target population. The target population for LCS differs in at least two important ways from the target populations for breast, cervical and colorectal cancer screening. Firstly, it is much more difficult to 'locate' this target group: lists of smokers and ex-smokers eligible for LCS are not readily available. Secondly, the mere fact that smokers have an 'unhealthy' lifestyle probably makes them less inclined to participate in preventive health care. Not surprisingly, in their review, recruitment from the hard to reach community was still colored in red by Field et al. [2016] as the only out of 12 areas related to LCS, requiring further evidence (10). Nevertheless, in the meantime several studies occurred, shining light on possible ways to improve recruitment from this target group. Shared decision-making is crucial and should be improved, by providing PCPs with the necessary tools, such as decision aids, to facilitate their job in this respect. However, since it was shown that there are substantial gaps in knowledge about LCS guidelines and reimbursement in family physicians and other PCPs and that they are not well-informed $(17,38)$, PCPs also have to be considered as a target group for education. Not only patient but also provider education should be developed to aid in shared decision-making opportunities (28).

There is a need for more creativity when it comes to information material. It will be necessary to go beyond the classic posters and leaflets but make use of films and digital platforms, which can in addition be more tailored to specific 
groups who participate least. The use of stepped and low burden materials could help at engaging people with a low social economic background. It is clear that there should be a balance between information on benefits and harms but it remains important to provide this information in a way that people can understand it. Personalized LC risk prediction calculators, or using a lot of statistics, for instance, could be too difficult to explain to patients. Subgroups, especially the more deprived, could be guided through their trajectory towards LCS by making use of patient navigation.

\section{Conclusions}

When we want LCS to become a success story, resulting in many lives of ex- and current smokers being saved, it will be necessary to reach the hard-to-reach. This will not be an easy task. This review shows that there are several gaps to be filled. Shared decision-making, a crucial element in guiding potential participants towards LCS, for instance, is insufficiently and inappropriately used because a substantial part of PCPs are not knowledgeable about the guidelines for LCS. Until now, too much focus has been put on educating the target groups for screening, meanwhile wrongly assuming that family physicians and other PCPs were ready to take up their task as a coach for potential LCS participants. Notwithstanding this, it remains of utmost importance that the screening program adapts to the target group and not the other way round. This does not only mean that the existing information materials should be more tailored to specific groups who participate least but also that alternative types of materials like information films should be used. It is clear that we are still at the beginning of the LCS era and that this review can only present an intermediate picture.

Indisputably, future research will have to further increase our insight.

\section{Acknowledgments}

Funding: None.

\section{Footnote}

Provenance and Peer Review: This article was commissioned by the Guest Editors (Paul Van Schil and Annemiek Snoeckx) for the series "Lung cancer screening" published in Translational Lung Cancer Research. The article has undergone external peer review.
Peer Review File: Available at http://dx.doi.org/10.21037/ tlcr-20-525

Conflict of Interest: Both authors have completed the ICMJE uniform disclosure form (available at http://dx.doi. org/10.21037/tlcr-20-525). The series "Lung cancer screening" was commissioned by the editorial office without any funding or sponsorship. The authors have no other conflicts of interest to declare.

Etbical Statement: The authors are accountable for all aspects of the work ensuring that questions related to the accuracy or integrity of any part of the work are appropriately investigated and resolved.

Open Access Statement: This is an Open Access article distributed in accordance with the Creative Commons Attribution-NonCommercial-NoDerivs 4.0 International License (CC BY-NC-ND 4.0), which permits the noncommercial replication and distribution of the article with the strict proviso that no changes or edits are made and the original work is properly cited (including links to both the formal publication through the relevant DOI and the license). See: https://creativecommons.org/licenses/by-nc-nd/4.0/.

\section{References}

1. American Cancer Society, Cancer Facts and Figures 2020. American Cancer Society, Atlanta, 2020.

2. Bray F, Ferlay J, Soerjomataram I, et al. Global cancer statistics 2018: GLOBOCAN estimates of incidence and mortality worldwide for 36 cancers in 185 countries. CA Cancer J Clin 2018;68:394-424.

3. de Groot PM, Carter BW, Gody MC, et al. Lung cancer screening-why do it? Tobacco, the history of screening, and future challenges. Semin Roentgenol 2015;50:72-81.

4. Aberle DR, Berg CD, Black WC, et al. The National Lung Screening Trial: overview and study design. Radiology 2011;258:243-53.

5. Aberle DR, Adams AM, Berg CD, et al. Reduced lungcancer mortality with low-dose computed tomographic screening. N Engl J Med 2011;365:395-409.

6. de Koning HJ, van der Aalst CM, de Jong PA, et al. Reduced Lung-Cancer Mortality with Volume CT Screening in a Randomized Trial. N Engl J Med 2020;382:503-13.

7. Rai A, Doria-Rose VP, Silvestri GA, et al. Evaluating Lung Cancer Screening Uptake, Outcomes, and Costs in the United States: Challenges With Existing Data and 
Recommendations for Improvement. J Natl Cancer Inst 2019;111:342-9.

8. Pham, D, Bhandari S, Oechsli M, et al. Lung cancer screening rates: Data from the lung cancer screening registry. 2018. ASCO Annual Meeting, Abstract 6504, 2018.

9. Yong PC, Sigel K, Rehmani S, et al. Lung Cancer Screening Uptake in the United States. Chest 2020;157:236-8.

10. Field JK, Devaraj A, Duffy SW, et al. CT screening for lung cancer: Is the evidence strong enough? Lung Cancer 2016;91:29-35.

11. Van Hal G. Participation in lung cancer screening: lessons learnt from the past. European Radiology Society (ERS) Research Seminar-Lung Cancer Screening: from Trial to Practice: Barcelona, 2018.

12. Ru Zhao Y, Xie X, de Koning HJ, et al. NELSON lung cancer screening study. Cancer Imaging 2011;11 Spec No A:S79-S84.

13. Cheung LC, Katki HA, Chaturvedi AK, et al., Preventing Lung Cancer Mortality by Computed Tomography Screening: The Effect of Risk-Based Versus U.S. Preventive Services Task Force Eligibility Criteria, 20052015. Ann Intern Med 2018;168:229-32.

14. Couraud S, Greillier L, Brignoli-Guibaudet L, et al. Current and Former Smokers: Who Wants To Be Screened? Clin Lung Cancer 2018;19:493-501.

15. Field JK, Duffy SW, Baldwin DR, et al. The UK Lung Cancer Screening Trial: a pilot randomised controlled trial of low-dose computed tomography screening for the early detection of lung cancer. Health Technol Assess 2016;20:1-146.

16. Quaife SL, Ruparel M, Beeken MJ, et al. The Lung Screen Uptake Trial (LSUT): protocol for a randomised controlled demonstration lung cancer screening pilot testing a targeted invitation strategy for high risk and 'hard-to-reach' patients. BMC Cancer 2016;16:281.

17. Kanodra NM, Pope C, Halbert CH, et al. Primary Care Provider and Patient Perspectives on Lung Cancer Screening: A Qualitative Study. Ann Am Thorac Soc 2016;13:1977-82.

18. Wang GX, Baggett TP, Pandharipande PV, et al. Barriers to Lung Cancer Screening Engagement from the Patient and Provider Perspective. Radiology 2019;290:278-87.

19. Li J, Chung S, Wei EK, et al. New recommendation and coverage of low-dose computed tomography for lung cancer screening: uptake has increased but is still low. BMC Health Serv Res 2018;18:525.

20. O'Brien MA, Sullivan F, Carson A, et al. Piloting electronic screening forms in primary care: findings from a mixed methods study to identify patients eligible for low dose CT lung cancer screening. BMC Fam Pract 2017;18:95.

21. López DB, Flores A, Miles EJ, et al. Assessing Eligibility for Lung Cancer Screening Among Women Undergoing Screening Mammography: Cross-Sectional Survey Results From the National Health Interview Survey. J Am Coll Radiol 2019;16:1433-9.

22. Eberth JM, Ersek JL, Terry LM, et al. Leveraging the Mammography Setting to Raise Awareness and Facilitate Referral to Lung Cancer Screening: A Qualitative Analysis. J Am Coll Radiol 2020;17:960-9.

23. Ali N, Lifford KJ, Carter B, et al. Barriers to uptake among high-risk individuals declining participation in lung cancer screening: a mixed methods analysis of the UK Lung Cancer Screening (UKLS) trial. BMJ Open 2015;5:e08254.

24. Schütte S, Dietrich D, Montet X, et al. Participation in lung cancer screening programs: are there gender and social differences? A systematic review. Public Health Rev 2018;39:23.

25. Quaife SL, Marlow LAV, McEwen A, et al. Attitudes towards lung cancer screening in socioeconomically deprived and heavy smoking communities: informing screening communication. Health Expect 2017;20:563-73.

26. Smits SE, McCutchan GM, Hanson JA, et al. Attitudes towards lung cancer screening in a population sample. Health Expect 2018;21:1150-8.

27. Quaife SL, Vrinten C, Ruparel M, et al. Smokers' interest in a lung cancer screening programme: a national survey in England. BMC Cancer 2018;18:497.

28. Hudson JN, Quinn GP, Wilson LE, et al. Evaluation of Promotional Materials To Promote Low-Dose Computed Tomography (LDCT) Screening to HighRisk Consumers and Health Care Providers. J Cancer Educ 2018;33:1043-51.

29. Chapple A, Ziebland S, McPherson A. Stigma, shame, and blame experienced by patients with lung cancer: qualitative study. Brit Med J 2004;328:1470-3.

30. Tonge JE, Atack M, Crosbie PA, et al. "To know or not to know horizontal ellipsis?" Push and pull in ever smokers lung screening uptake decision-making intentions. Health Expect 2019;22:162-72.

31. Byrne MM, Lillie SE, Studts A, Lung cancer screening in a community setting: Characteristics, motivations, and attitudes of individuals being screened. Health Psychol Open 2019;6:2055102918819163. 
32. Han PKJ, Lary C, Black A, et al. Effect of Personalized Risk Information on Patients Referred for Lung Cancer Screening With Low-Dose CT. Med Decis Making 2019;39:950-61.

33. Norman R, Moorin R, Maxwell S, et al. Public Attitudes on Lung Cancer Screening and Radiation Risk: A BestWorst Experiment. Value Health 2020;23:495-505.

34. Kok WH, Yu-Lin AB, Shah SA, et al. Determining the perception of a lung cancer screening programme among high-risk patients in a tertiary referral centre, Kuala Lumpur. Proceedings of Singapore Healthcare 2020;29:19-24.

35. Draucker CB, Rawl SM, Vode E, et al. Understanding the decision to screen for lung cancer or not: A qualitative analysis. Health Expect 2019;22:1314-21.

36. Elwyn G, Frosch D, Thomson R, et al. Shared decision making: a model for clinical practice. J Gen Intern Med 2012;27:1361-7.

37. Greene PA, Sayre G, Heffner JL, et al. Challenges to Educating Smokers About Lung Cancer Screening: a Qualitative Study of Decision Making Experiences in Primary Care. J Cancer Educ 2019;34:1142-9.

38. Ersek JL, Eberth JM, McDonnell KK, et al., Knowledge of, attitudes toward, and use of low-dose computed tomography for lung cancer screening among family physicians. Cancer 2016;122:2324-31.

39. Bui NC, Lee YY, Suh M, et al. Beliefs and Intentions to Undergo Lung Cancer Screening among Korean Males. Cancer Res Treat 2018;50:1096-105.

40. Lillie SE, Fua SS, Fabbrinic AE, et al. What factors do patients consider most important in making lung cancer screening decisions? Findings from a demonstration project conducted in the Veterans Health Administration. Lung Cancer 2017;104:38-44.

41. Sin MK, Ha A, Taylor V. Sociocultural Barriers to Lung Cancer Screening Among Korean Immigrant Men. J Community Health 2016;41:790-7.

42. Moizs M, Bajzik G, Lelovics Z, et al. Characterization of Individuals Taking Part in Low Dose Computed Tomography (LDCT) Screening Program. Pathol Oncol Res 2015;21:1167-73.

43. Roth JA, Carter-Harris L, Brandzel S, et al. A qualitative study exploring patient motivations for screening for lung cancer. PLoS One 2018;13:e0196758.

44. Prout HC, Barham A, Bongard E, et al. Patient understanding and acceptability of an early lung cancer diagnosis trial: a qualitative study. Trials 2018;19:419.

45. Cataldo JK. High-risk older smokers' perceptions, attitudes, and beliefs about lung cancer screening. Cancer Med 2016;5:753-9.

46. Barbone F, Barbiero F, Belvedere O, et al. Impact of low-dose computed tomography screening on lung cancer mortality among asbestos-exposed workers. Int J Epidemiol 2018;47:1981-91.

47. Chalian H, Khoshpouri P, Assari S. Demographic, Social, and Behavioral Determinants of Lung Cancer Perceived Risk and Worries in a National Sample of American Adults; Does Lung Cancer Risk Matter? Medicina 2018;54:97.

48. Pedersen JH, TØnnesen P, Ashraf H. Smoking cessation and lung cancer screening. Ann Transl Med 2016;4:157.

49. Carter-Harris L, Davis LL, Rawl SM. Lung Cancer Screening Participation: Developing a Conceptual Model to Guide Research. Res Theory Nurs Pract 2016;30:333-52.

50. Carter-Harris L, Slaven JE, Monohan P, et al. Development and Psychometric Evaluation of the Lung Cancer Screening Health Belief Scales. Cancer Nurs 2017;40:237-44.

51. Evans WK, Flanagan WM, Miller AB, et al. Implementing low-dose computed tomography screening for lung cancer in Canada: implications of alternative at-risk populations, screening frequency, and duration. Curr Oncol 2016;23:e179-87.

52. Ruparel M, Quaife SL, Ghimire B, et al. Impact of a Lung Cancer Screening Information Film on Informed Decision-making: A Randomized Trial. Ann Am Thorac Soc 2019;16:744-51.

53. Jessup DL, Glover M, Daye D, et al. Implementation of Digital Awareness Strategies to Engage Patients and Providers in a Lung Cancer Screening Program: Retrospective Study. J Med Internet Res 2018;20:e52.

54. Quaife SL, Ruparel M, Dickson JL, et al. Lung Screen Uptake Trial (LSUT): Randomized Controlled Clinical Trial Testing Targeted Invitation Materials. Am J Respir Crit Care Med 2020;201:965-75.

55. Percac-Lima S, Ashburner JM, Rigotti NA, et al. Patient navigation for lung cancer screening among current smokers in community health centers a randomized controlled trial. Cancer Med 2018;7:894-902.

Cite this article as: Van Hal G, Diab Garcia P. Lung cancer screening: targeting the hard to reach-a review. Transl Lung Cancer Res 2021;10(5):2309-2322. doi: 10.21037/tlcr-20-525 


\begin{tabular}{|c|c|c|c|c|}
\hline Article ID & Author & Year & Title & Journal \\
\hline 1 & Ali et al. & 2015 & $\begin{array}{l}\text { Barriers to uptake among high-risk individuals declining participation in lung } \\
\text { cancer screening: a mixed methods analysis of the UK Lung Cancer } \\
\text { Screening (UKLS) trial }\end{array}$ & BMJ Open \\
\hline 2 & Barbone et al. & 2018 & $\begin{array}{l}\text { Impact of low-dose computed tomography screening on lung cancer } \\
\text { mortality among asbestos-exposed workers }\end{array}$ & $\begin{array}{l}\text { International Journal of } \\
\text { Epidemiology }\end{array}$ \\
\hline 3 & Bui et al. & 2018 & $\begin{array}{l}\text { Beliefs and Intentions to Undergo Lung Cancer Screening among Korean } \\
\text { Males }\end{array}$ & $\begin{array}{l}\text { Cancer Research and } \\
\text { Treatment }\end{array}$ \\
\hline 4 & Byrne et al. & 2019 & $\begin{array}{l}\text { Lung cancer screening in a community setting: Characteristics, motivations, } \\
\text { and attitudes of individuals being screened }\end{array}$ & $\begin{array}{l}\text { Health Psychology } \\
\text { Open }\end{array}$ \\
\hline 5 & $\begin{array}{l}\text { Carter-Harris } \\
\text { et al. }\end{array}$ & 2016 & $\begin{array}{l}\text { Lung Cancer Screening Participation: Developing a Conceptual Model to } \\
\text { Guide Research }\end{array}$ & $\begin{array}{l}\text { Research and Theory } \\
\text { for Nursing Practice }\end{array}$ \\
\hline 6 & Cataldo & 2016 & $\begin{array}{l}\text { High-risk older smokers' perceptions, attitudes, and beliefs about lung } \\
\text { cancer screening }\end{array}$ & Cancer Medicine \\
\hline 7 & Chalian et al. & 2018 & $\begin{array}{l}\text { Demographic, Social, and Behavioral Determinants of Lung Cancer } \\
\text { Perceived Risk and Worries in a National Sample of American Adults; Does } \\
\text { Lung Cancer Risk Matter? }\end{array}$ & Medicina-Lithuania \\
\hline 8 & Chapple et al. & 2004 & $\begin{array}{l}\text { Stigma, shame, and blame experienced by patients with lung cancer: } \\
\text { qualitative study }\end{array}$ & British Medical Journal \\
\hline 9 & Cheung et al. & 2018 & $\begin{array}{l}\text { Preventing Lung-Cancer Mortality by CT Screening: The Effect of } \\
\text { Risk-based versus USPSTF Eligibility Criteria, 2005-2015 }\end{array}$ & $\begin{array}{l}\text { Annals of Internal } \\
\text { Medicine }\end{array}$ \\
\hline 10 & Couraud et al. & 2018 & Current and Former Smokers: Who Wants To Be Screened? & Clinical Lung Cancer \\
\hline 11 & Draucker et al. & 2019 & $\begin{array}{l}\text { Understanding the decision to screen for lung cancer or not: A qualitative } \\
\text { analysis }\end{array}$ & Health Expectations \\
\hline 12 & Eberth et al. & 2020 & $\begin{array}{l}\text { Leveraging the Mammography Setting to Raise Awareness and Facilitate } \\
\text { Referral to Lung Cancer Screening: A Qualitative Analysis }\end{array}$ & $\begin{array}{l}\text { Journal of the } \\
\text { American College of } \\
\text { Radiology }\end{array}$ \\
\hline 13 & Ersek et al. & 2016 & $\begin{array}{l}\text { Knowledge of, attitudes toward, and use of low-dose computed tomography } \\
\text { for lung cancer screening among family physicians }\end{array}$ & Cancer \\
\hline 14 & Evans et al. & 2016 & $\begin{array}{l}\text { Implementing low-dose computed tomography screening for lung cancer in } \\
\text { Canada: inmplications of alternative at-risk populations, screening frequency, } \\
\text { and duration }\end{array}$ & Current oncology \\
\hline 15 & Field et al. & 2016 & CT screening for lung cancer: Is the evidence strong enough? & Lung Cancer \\
\hline 16 & Field et al. & 2016 & $\begin{array}{l}\text { The UK Lung Cancer Screening Trial: a pilot randomised controlled trial of } \\
\text { low-dose computed tomography screening for the early detection of lung } \\
\text { cancer }\end{array}$ & $\begin{array}{l}\text { Health Technology } \\
\text { Assessment }\end{array}$ \\
\hline 17 & Greene et al. & 2019 & $\begin{array}{l}\text { Challenges to Educating Smokers About Lung Cancer Screening: a } \\
\text { Qualitative Study of Decision Making Experiences in Primary Care }\end{array}$ & $\begin{array}{l}\text { Journal of Cancer } \\
\text { Education }\end{array}$ \\
\hline 18 & Han et al. & 2019 & $\begin{array}{l}\text { Effects of Personalized Risk Information on Patients Referred for Lung } \\
\text { Cancer Screening With Low-Dose CT }\end{array}$ & $\begin{array}{l}\text { Medical Decision } \\
\text { Making }\end{array}$ \\
\hline 19 & Hudson et al. & 2018 & $\begin{array}{l}\text { Evaluation of Promotional Materials To Promote Low-Dose Computed } \\
\text { Tomography (LDCT) Screening to High-Risk Consumers and Health Care } \\
\text { Providers }\end{array}$ & $\begin{array}{l}\text { Journal of Cancer } \\
\text { Education }\end{array}$ \\
\hline 20 & Jessup et al. & 2018 & $\begin{array}{l}\text { Implementation of Digital Awareness Strategies to Engage Patients and } \\
\text { Providers in a Lung Cancer Screening Program: Retrospective Study }\end{array}$ & $\begin{array}{l}\text { Journal of Medical } \\
\text { Internet Research }\end{array}$ \\
\hline 21 & Kanodra et al. & 2016 & $\begin{array}{l}\text { Primary Care Provider and Patient Perspectives on Lung Cancer Screening } \\
\text { A Qualitative Study }\end{array}$ & $\begin{array}{l}\text { Annals of the American } \\
\text { thoracic society }\end{array}$ \\
\hline 22 & Kok et al. & 2020 & $\begin{array}{l}\text { Determining the perception of a lung cancer screening programme among } \\
\text { high-risk patients in a tertiary referral centre, Kuala Lumpur }\end{array}$ & $\begin{array}{l}\text { Proceedings of } \\
\text { Singapore healthcare }\end{array}$ \\
\hline 23 & Liet al. & 2018 & $\begin{array}{l}\text { New recommendation and coverage of low-dose computed tomography for } \\
\text { lung cancer screening: uptake has increased but is still low }\end{array}$ & $\begin{array}{l}\text { BMC Health Services } \\
\text { Research }\end{array}$ \\
\hline 24 & Lillie et al. & 2017 & $\begin{array}{l}\text { What factors do patients consider most important in making lung cancer } \\
\text { screening decisions? Findings from a demonstration project conducted in } \\
\text { the Veterans Health Administration }\end{array}$ & Lung cancer \\
\hline 25 & Lopez et al. & 2019 & $\begin{array}{l}\text { Assessing Eligibility for Lung Cancer Screening Among Women Undergoing } \\
\text { Screening Mammography: Cross-Sectional Survey Results From the } \\
\text { National Health Interview Survey }\end{array}$ & $\begin{array}{l}\text { Journal of the } \\
\text { American College of } \\
\text { Radiology }\end{array}$ \\
\hline 26 & Moizs et al. & 2015 & $\begin{array}{l}\text { Characterization of Individuals Taking Part in Low Dose Computed } \\
\text { Tomography (LDCT) Screening Program }\end{array}$ & $\begin{array}{l}\text { Pathology and } \\
\text { Oncology Research }\end{array}$ \\
\hline 27 & Norman et al. & 2020 & $\begin{array}{l}\text { Public Attitudes on Lung Cancer Screening and Radiation Risk: A } \\
\text { Best-Worst Experiment }\end{array}$ & Value in Health \\
\hline 28 & O'Brien et al. & 2017 & $\begin{array}{l}\text { Piloting electronic screening forms in primary care: findings from a mixed } \\
\text { methods study to identify patients eligible for low dose CT lung cancer } \\
\text { screening }\end{array}$ & BMC Family Practice \\
\hline 29 & $\begin{array}{l}\text { Percac-Lima } \\
\text { et al. }\end{array}$ & 2018 & $\begin{array}{l}\text { Patient navigation for lung cancer screening among current smokers in } \\
\text { community health centers a randomized controlled trial }\end{array}$ & Cancer Medicine \\
\hline 30 & Pedersen et al. & 2016 & Smoking cessation and lung cancer screening & $\begin{array}{l}\text { Annals of Translational } \\
\text { Medicine }\end{array}$ \\
\hline 31 & $\operatorname{Pr}$ & 2018 & $\begin{array}{l}\text { Patient understanding and acceptability of an early lung cancer diagnosis } \\
\text { trial: a qualitative study }\end{array}$ & Trials \\
\hline 32 & Quaife et al. & 2016 & $\begin{array}{l}\text { : protocol for a randomised controlled } \\
\text { pilot testing a targeted invitation } \\
\text { ach' patients }\end{array}$ & BMC Cancer \\
\hline 33 & Qu & 2017 & $\begin{array}{l}\text { Attitudes towards lung cancer screening in socioeconomically deprived and } \\
\text { heavy smoking communities: informing screening communication }\end{array}$ & Health $E_{x}$ \\
\hline 34 & Quaife et al. & 2018 & $\begin{array}{l}\text { Smokers' interest in a lung cancer screening programme: a national survey } \\
\text { in England }\end{array}$ & BMC Cancer \\
\hline 35 & Quaife et al. & 2020 & $\begin{array}{l}\text { Lung Screen Uptake Trial (LSUT): Randomize } \\
\text { Testing Targeted Invitation Materials }\end{array}$ & $\begin{array}{l}\text { American Journal of } \\
\text { Respiratory and } \\
\text { Critical Care Medicine }\end{array}$ \\
\hline 36 & Rai et al. & 2019 & $\begin{array}{l}\text { Evaluating Lung Cancer Screening Uptake, Outcomes, and Costs in the } \\
\text { United States: Challenges With Existing Data and Recommendations for } \\
\text { Improvement }\end{array}$ & $\begin{array}{l}\text { Journal of the National } \\
\text { Cancer Institute }\end{array}$ \\
\hline 37 & $\mathrm{Rc}$ & 2018 & $\begin{array}{l}\text { A qualitative study exploring patient motivations for screening for lung } \\
\text { cancer }\end{array}$ & PLos One \\
\hline 38 & Ruparel et al. & 2019 & $\begin{array}{l}\text { Impact of a Lung Cancer Screening Information Film on } \\
\text { Decision-making: A Randomized Trial }\end{array}$ & $\begin{array}{l}\text { Annals of the } \\
\text { Thoracic Soc }\end{array}$ \\
\hline 39 & Schütte et al. & 2018 & $\begin{array}{l}\text { Participation in lung cancer screening programs: are there gender and social } \\
\text { differences? A systematic review }\end{array}$ & Public Health Reviews \\
\hline 40 & Sin et al. & 2016 & $\begin{array}{l}\text { Sociocultural Barriers to Lung Cancer Screening Among } \\
\text { Men }\end{array}$ & $\begin{array}{l}\text { Journal of Community } \\
\text { Health }\end{array}$ \\
\hline 41 & Smits et al. & 2018 & Attitudes towards lung cancer screening in a population sample & Health Expectations \\
\hline 42 & Tonge et al. & 2019 & $\begin{array}{l}\text { "To know or not to know...?" Push and pull in ever smokers lung screening } \\
\text { uptake decision-making intentions }\end{array}$ & Health Expectations \\
\hline 43 & War & 2019 & erspective & Radiology \\
\hline
\end{tabular}

